\title{
Spirituality and Older Adults: Ethical Guidelines to Enhance Service Provision
}

\author{
David R. Hodge \\ Robin P. Bonifas \\ Rita Jing-Ann Chou
}

\begin{abstract}
Spirituality plays an important role in the lives of many older adults. Consequently, it is not surprising that gerontological social workers frequently engage spirituality in practice settings. The paucity of training gerontological workers have received on this topic, however, is a cause for concern. To help equip workers, three ethical principles are proposed to guide interactions in the area of spirituality. These principles can be summarized as: 1) client autonomy, 2) spiritual competence, and 3) professional competence. The application of these principles in practice settings will enhance the ability of gerontological social workers to interact with older adults' spirituality in a professional and ethical manner.
\end{abstract}

Key Words: Spirituality, religion, strengths, ethical practice, older adults

\section{INTRODUCTION}

Spirituality and religion are important constructs in the lives of many older adults (Taylor, Chatters, \& Jackson, 2007). For instance, among those 65 and older, 72 percent report that religion is very important in their lives (Newport, 2006). This represents the highest percentage reported by any of the age groups surveyed by the Gallup organization (Newport, 2006).

Spiritual beliefs and practices often play a central role in helping older adults navigate life-challenges (Barusch, 1999; Cabassa, 2007; Lawrence et al., 2006). Research has associated spirituality with: health and wellness (Koenig, McCullough \& Larson, 2001; Vink, Aartsen, \& Schoevers, 2008), life satisfaction (Yoon \& Lee, 2007), and selfesteem (Keyes \& Reitzes, 2007). Similarly, spirituality has been linked to the ability to cope with a variety of issues, including adversity (Barusch, 1999), anxiety (Rajagopal, MacKenzie, Bailey, \& Lavizzo-Mourey, 2002), depression (Koenig, 2007a), fear of falling (Zhang, Ishikawa-Takata, Yamazaki, Morita, \& Ohta, 2006), HIV (Vance, 2006), vision loss (Brennan, 2002), and lifetime trauma (Krause, 2009). In short, the extant empirical research suggests that spirituality is typically a strength in the lives of older adults.

In light of this research, some observers have suggested that older adults' spiritual beliefs can be harnessed to enhance outcomes (Koenig, Larson, \& Matthews, 1996; Lewis, 2001; Moberg, 2005; Nelson-Becker, Nakashima, \& Canda, 2007). Since

David R. Hodge, Ph.D., is Assistant Professor, School of Social Work, Arizona State University, and Senior Nonresident Fellow, Program for Research on Religion and Urban Civil Society, University of Pennsylvania. Robin P. Bonifas, Ph.D. is Assistant Professor, School of Social Work, Arizona State University. Rita Jing-Ann Chou, Ph.D., is Assistant Professor, College of Social Work, University of South Carolina. Preparation of this paper was supported by a grant from the John A. Hartford Foundation. 
spirituality is often related to outcomes of interest to gerontological social workers, it is argued that practitioners should tap all relevant client strengths to address problems. Consequently, it is perhaps not surprising that the existing research suggests that most gerontological workers are, at least in some form, addressing the spiritual dimension in their practices with older adults (Murdock, 2005).

Incorporating spirituality into practice in an ethical manner may, however, pose somewhat of a challenge to gerontological social workers. Despite widespread interest in tapping clients' spiritual strengths to address problems, most gerontological practitioners appear to have received little or no training on the topic during their graduate educations (Murdock, 2005; Sheridan, 2009). These self-reports have been corroborated by a content analysis of widely used social work foundation practice textbooks, which found minimal content on older adults and spirituality and religion across approximately 10,000 pages of surveyed text (Tompkins, Larkin, \& Rosen, 2006).

The lack of training is particularly concerning in light of the vulnerabilities commonly associated with aging. Although many individuals in later life continue to lead productive lives, aging is often associated with increasing cognitive, emotional, and physical challenges (Aldwin, Park, \& Spiro, 2007). Further, it is often at points of heightened vulnerability that gerontological social workers encounter older adults. Without proper training workers may engage in unethical practice, perhaps even unknowingly, that engenders harm.

The available research on this topic, although limited, corroborates this concern. A national survey of direct practitioners affiliated with NASW $(N=2,069)$ found that only $17 \%$ agreed that their social work colleagues possess the knowledge to appropriately address spirituality in practice settings (Canda \& Furman, 1999). This assessment was supported by an analysis of the qualitative data (Canda, Nakashima, \& Furman, 2004). Another study that examined practitioners' reliance upon formal ethical frameworks reportedly found that many practitioners were not basing practice decisions on ethical principles (Sheridan, 2009).

In light of these findings, calls have appeared in the literature highlighting the need for more training on ethical principles (Canda et al., 2004; Murdock, 2005; Sheridan, 2009). Murdock (2005), for instance, has specifically mentioned this need regarding gerontological social workers. In other words, gerontological workers' practice with older adults may be enhanced by the delineation of ethical principles related to spirituality (Murdock, 2005).

Accordingly, the purpose of this paper is to provide gerontological workers with some ethical principles to guide interactions regarding client spirituality. Applying these principles will enable workers to approach older adults' spirituality in a professional and ethical manner that helps safeguard older adults' well-being. Before discussing these principles, however, conceptualizations of spirituality and religion are overviewed. 


\section{SPIRITUALITY AND RELIGION: DISTINCTIONS AND CONNECTIONS}

In academic circles it has become increasingly common to conceptualize spirituality and religion as distinct but overlapping constructs (Canda \& Furman, 2010; Derezotes, 2006). Spirituality is commonly defined as a person's existential relationship with God or the Transcendent (Hodge, 2005a; Wuthnow, 2007). Religion can be understood as a shared set of beliefs and practices-developed in community with people who have similar understandings of the Transcendent-which is designed to mediate an individual's relationship with the Transcendent (Geppert, Bogenschutz, \& Miller, 2007; Koenig et al., 2001). At the risk of oversimplification, spirituality emphasizes the personal and religion the communal.

While these types of distinctions are widespread in academic circles, it is important to note that such demarcations are less frequent among members of the general population, and perhaps older adults in particular (Moberg, 2005). The vast majority of older adults self-describe as both spiritual and religious (Musick, Traphagan, Koenig \& Larson, 2000). In short, many older adults appear to use both terms to connote similar ideas (Musick et al., 2000).

It can also be useful to envision spirituality as a continuous construct (Gallup \& Jones, 2000; Miller, 1998). This continuum ranges, on one end, from those who are uninterested in spirituality, to those for whom spirituality is just one of many lifedimensions, through to those on the other end of the continuum for whom spirituality plays the primary role in shaping beliefs and actions (Gallup \& Lindsay, 1999; Van Hook, Hugen, \& Aguilar, 2001). While ethical practice is imperative across the continuum, older adults on the latter end of the continuum may be particularly at-risk for unethical treatment.

\section{ETHICAL PRINCIPLES TO GUIDE INTERACTIONS WITH OLDER ADULT SPIRITUALITY}

As texts on ethical practice indicate, many ethical principles should guide practice decisions (Reamer, 2006). This paper focuses on three interrelated principles that may be particularly pertinent in guiding gerontological workers' interactions with older adult spirituality. These principles are among the most commonly cited in the literature calling for additional training on ethics in practice settings (Canda et al., 2004; Murdock, 2005; Sheridan, 2009).

In brief, these principles can be summarized as follows: 1) respect for client autonomy, 2) sufficient competency in the client's spiritual tradition, and 3) practicing within the boundaries of professional competency. It may be helpful to note that these principles are interrelated. Thus, although discussed separately, they inform one another when working with older adults in practice settings.

\section{Client Autonomy}

As indicated in the NASW Code of Ethics (1999), respect for client autonomy is a fundamental social work value. The importance of this value is accentuated when dealing 
with spirituality, which is often a highly personal and sensitive subject among clients (Hodge, 2006a). Older adults may be particularly sensitive to breaches of client selfdetermination due to the importance they often ascribe to spirituality (Lewis, 2001).

Autonomy can be violated in many ways. For example, imposing spiritual beliefs that are inconsistent with clients' spiritual narrative contravenes self-determination (Canda \& Furman, 2010). This might take the form of using terminology that is foreign to older adults' spiritual narrative. Similarly, assuming that spiritually committed older adults want to incorporate spirituality into treatment can also represent a more subtle violation of self-determination. Some spiritually committed clients may desire to keep private the spiritual dimension of their lives.

Alternatively, ignoring spirituality when older adults desire to integrate their spiritual assets into the helping process also represents a breach of autonomy (Nelson-Becker, 2005). Clients often believe that spirituality plays an essential role in ameliorating, or coping with, problems (Cabassa, 2007; Lawrence et al., 2006). Disregarding clients' expressed desires also demonstrates a lack of respect for their autonomy.

Likewise, waiting for clients to raise the topic can also be problematic. For instance, elderly clients who want to have their spirituality taken into account during service provision may not initiate a discussion of spirituality. Because of its highly personal nature, older adults may not broach the subject of spirituality unless directly asked (Nelson-Becker et al., 2007).

To fully respect clients' wishes, interactions should typically be preceded by a brief spiritual assessment to determine interest in spirituality, religious tradition, and other basic, preliminary information (Nelson-Becker et al., 2007). Indeed, the Joint Commission - the largest and most influential health care accrediting body in the United States-now requires such assessments in hospitals, nursing homes, home care organizations, and many other health care settings providing services to older adults (Hodge, 2006a; Koenig, 2007b). Such an assessment can be used to create a supportive space in which client self-determination is honored (Hodge, 2004). Both Hodge (2006a) and Koenig (2007b) have developed brief spiritual assessment tools that are congruent with the Joint Commissions' accrediting requirements.

The use of informed consent is an important mechanism for safeguarding autonomy (Miller, 2003). If a brief assessment reveals that spirituality is potentially relevant to professional practice, informed consent should be obtained before proceeding with a more extensive examination of how spirituality might be incorporated into practice. Initially, consent may be obtained on an informal, verbal basis. If the ensuing conversation confirms the relevance of spirituality, then a more formal, written consent might be considered to clarify the nature, scope, and role of spirituality in the helping process.

Ideally, however, informed consent should be viewed as ongoing process rather than an event-specific procedure (Hodge, 2006a). Practitioners should continuously monitor clients' responses to ensure that they remain fully supportive of the continuing dialogue. Older adults' wishes can easily change over time. 
In some cases, for example, clients may communicate a desire to integrate spirituality into practice, but later change their minds, perhaps due to perceived lack of sensitivity to their spiritual values. The initial brief assessment may go well, for example, indicating the use of a comprehensive assessment to explore possible ways in which older adults' spiritual strengths might be operationalized (Hodge, 2006a). However, during the comprehensive assessment gerontological workers may, perhaps inadvertently, make comments about the clients' spiritual tradition that are perceived to be offensive.

Alternatively, clients may initially indicate that they are uninterested in discussing spirituality. In some such cases, clients may be hesitant to trust workers with a sacred life-dimension (Lewis, 2001). The potential for such a response is heightened given the lack of training in spirituality most gerontological workers report and the often volatile nature of the subject matter (Murdock, 2005). Trust may be developed over time, however, resulting in a change in disposition. The following principle is intrinsically linked to the process of developing and maintaining trust.

\section{Spiritual Competence}

The second principle that should guide interactions with client spirituality is spiritual competence. Due in large part to changing immigration patterns, the population of older adults in the United States is characterized by increasing spiritual diversity (Berkman, Maramaldi, Breon, \& Howe, 2002; Melton, 2003). The numbers of Buddhists, Hindus, and Muslims - to list just some traditions-have increased substantially during the past few decades (Smith, 2002; Smith \& Seokho, 2005). They join a spiritual landscape populated by various Protestant, Catholic, and Jewish faiths, each with their own distinct value system (Koenig, 1998; Richards \& Bergin, 2000; Van Hook et al., 2001). As a result, the United States is now perhaps the most spiritually diverse nation on the planet (Eck, 2001).

Spiritual competence can be understood as a distinct expression of cultural competence that deals with spiritually-informed cultures (Sue \& Sue, 2008). The construct can be conceptualized as a continuous, life-long process whereby workers develop: 1) a growing awareness of their own value-informed spiritual worldview and its assumptions, limitations, and biases, 2) an empathic understanding of the client's spiritual worldview, and 3) the ability to design and implement interventions that resonate with their client's spiritual worldview (Hodge \& Bushfield, 2006). Thus, spiritual competence is a dynamic set of attitudes, knowledge, and skills regarding various spiritual traditions, which can be developed over time with different populations (Sue \& Sue, 2008).

Awareness of one's worldview plays an important role in managing spiritual countertransference (Frame, 2003; Genia, 2000; Hodge, 2003; Miller, 2003). When encountering spiritually different worldviews, unresolved personal issues may unconsciously affect interactions. For instance, gerontological workers who have rejected their family of origin's religion may consciously or unconsciously react when encountering older adults who affirm that particular value system. Subtle expressions of disapproval can damage the worker's relationship with clients. To manage these types of 
reactions, self-exploration can be a particularly useful tool, especially when conducted in a supervisory context with spiritually competent practitioners.

Toward this end, gerontological social workers might consider administering spiritual self-assessments (Hodge \& Derezotes, 2008). A number of comprehensive spiritual assessment tools have been developed which highlight different aspects of spirituality using diagrammatic approaches that lend themselves to self-assessments (Hodge, 2005b). Included among these pictorial approaches are spiritual lifemaps (Hodge, 2005a), spiritual genograms (Hodge, 2001), spiritual eco-maps (Hodge \& Williams, 2002), and spiritual ecograms (Hodge, 2005c). Practitioners might conduct a spiritual selfassessment with each of these tools, and then reflect upon the implications of their spirituality as it intersects practice with various client populations. This exercise helps acquaint practitioners with the strengths and limitations of various approaches to spiritual assessment (Hodge, 2005d), while facilitating self-understanding of one's personal worldview.

Cultivating awareness of the strengths and limitations of one's worldview helps develop a positive understanding of culturally different spiritual worldviews. Demonstrating empathetic awareness of widespread beliefs and practices within older adults' various traditions can meta-communicate respect for, and acceptance of, clients' spiritual choices. In turn, this can help alleviate the concerns among some older adults that practitioners will not respect their spiritual values (Lewis, 2001).

It is at this point of empathic understanding that spiritual interventions can be coconstructed with older adults. While developing fluency in all spiritual traditions may be unrealistic, it is usually possible to developing a working knowledge of traditions that are commonly encountered in practice. For instance, practitioners living in Utah might familiarize themselves with beliefs and practices that are widely affirmed within the Latter Day Saints tradition.

While working to cultivate an understanding of various traditions, it is important to remember the diversity that exists with each individual tradition (Hodge, 2002; Hodge, 2005e). Individuals who self-identify as members of a given spiritual tradition can affirm a wide variety of beliefs, including beliefs that are at odds with the norms of the tradition. As a result, it is helpful to view traditions as flexible templates that suggest, rather than require, the presence of particular beliefs and practices.

While each client's spiritual narrative is individualized by the client's unique experience of the Transcendent, it is also typically expressed within the parameters of a spiritual tradition (Musick et al., 2000). Developing familiarity with common norms can help practitioners use more culturally relevant language, avoid offensive comments, and suggest possible intervention strategies. While older adults must always be encouraged to affirm, reject, or modify the options provided by practitioners, the ability to tentatively offer working models can facilitate engagement and salutary outcomes.

A number of options exist for developing understanding of various traditions. For instance, reading content on frequently encountered spiritual traditions-preferably written by cultural insiders, or sympathizers — can aid understanding of common norms 
(Ginsberg, 1999). Toward this end, a number of resources have appeared in the academic literature (Koenig, 1998; Richards \& Bergin, 2000; Van Hook et al., 2001). Visits to local houses of worship can also help in enhancing knowledge. Congregants are often willing to answer questions about their spiritual tradition.

Clergy are also frequently open to sharing information about common norms within their tradition (Harr, Openshaw, \& Moore, 2006). As will be discussed in more depth below, it is typically productive to form collaborative relationships with clergy whenever possible (Benes, Walsh, McMinn, Dominquez, \& Aikins, 2000; Edwards, Brian, McMinn, \& Dominguez, 1999). Many older adults exhibit a high degree of trust in their clergy (Oppenheimer, Flannelly, \& Weaver, 2004). In addition to helping gerontological practitioners understand the norms within spiritual traditions, clergy are also front-line mental health workers (Oppenheimer et al., 2004). In other words, older adults often present to clergy first with mental health problems. Forming collaborative relationships with clergy can enhance overall service provision to clients (Harr et al., 2006).

Another option for developing understanding of various spiritual traditions is to cultivate relationships with practitioners who are more conversant in the norms of a particular tradition. Some practitioners have developed specialized knowledge of spiritual beliefs and practices within given traditions (Nielsen, 2004). Consulting with such individuals can be particularly helpful as they are often well-versed in how the norms within a tradition intersect health and mental health issues.

If older adults are at-risk of experiencing culturally insensitive practice, referral to a more spiritually competent practitioner should be considered (Reamer, 2006). Some gerontological workers may not have the necessary skills and knowledge to work with older adults from some traditions. Others may feel that worker/client value differences preclude an effective working relationship. Still others may feel the value differences are surmountable, but they have not fully worked through the countertransference issues. Referral may also be relevant in the context of the next ethical principle, although for somewhat different reasons.

\section{Professional Competence}

The third ethical principle is to practice within the boundaries of professional competence. As is the case with the above principles, it is drawn from the NASW Code of Ethics (1999, p. 1.04a) and has particular relevance to the area of spirituality. Although closely related to the above content, it can be distinguished from the concept of spiritual competency in some important aspects. Namely, spiritual competency emphasizes training related to workers' interpersonal capabilities while professional competence emphasizes training regarding interventions designed to ameliorate problems (Resnicow, Soler, Braithwaite, Ahluwalia, \& Butler, 2000).

For instance, when exploring spirituality with older adults, it is important to ensure the dialogue is focused on addressing clients' problems (Hodge, 2005a). Considerable overlap exists between counseling, a practice designed to minimize clients' difficulties, and spiritual direction, a practice designed to increase a person's intimacy with God or the Transcendent (Tan, 2003). Gerontological workers and spiritual directors can, in the 
context of working with older adults, address both content areas: spirituality and problems. Although the content discussed within each area may be similar, the aims tend to differ (Ganje-Fling \& McCarthy, 1991). A gerontological worker discusses spirituality with the goal of increasing the client's ability to ameliorate the problem. Alternatively, a spiritual director discusses problems with the goal of increasing the client's intimacy with God.

Table 1 summarizes some common differences between therapy and spiritual direction. Neither enterprise sanctions authoritarian relationships, preaching, or advice giving (Tan, 2003). Both therapy and spiritual direction are conversationally based enterprises that are essentially egalitarian and growth-oriented in nature. Within this context, however, they do tend to stress different points. Understanding these different areas of emphasis can assist practitioners to remain within the parameters of their area of professional competence.

Table 1: $\quad$ Distinctions between Therapy and Spiritual Direction

\begin{tabular}{|c|c|}
\hline $\mathrm{Em}$ & Emphasis in Spiritual Direction \\
\hline 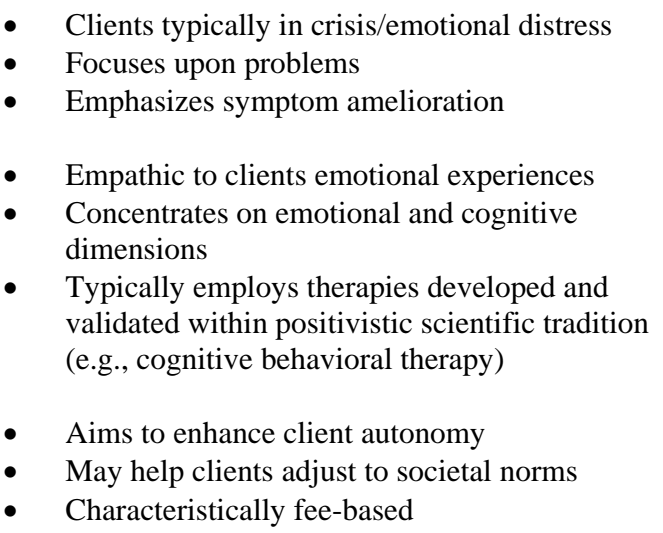 & $\begin{array}{l}\text { - } \quad \text { Clients often exhibiting wellness } \\
\text { - } \quad \text { Focuses upon spiritual growth } \\
\text { - } \quad \text { Emphasizes the link between life experience and } \\
\text { - } \quad \text { Conpathic to the Spirit of God } \\
\text { - } \quad \text { Typiritual experiences) } \\
\text { over centuries of experience in a given spiritual } \\
\text { tradition (e.g., spiritual exercises, such as } \\
\text { - } \quad \text { Aimeditation) } \\
\text { - } \quad \text { Helps clients adjust to spiritual norms } \\
\text { Characteristically offered without cost }\end{array}$ \\
\hline
\end{tabular}

Based upon Ganje-Fling and McCarthy (1991) and Tan (2003)

Gerontological workers-perhaps especially those interested in spirituality-can inadvertently fall into the role of a spiritual director when exploring the issue of spirituality. For most workers, however, this role falls outside the parameters of their professional competence (Richards \& Bergin, 2005). It is important to be aware of such dynamics and ensure that the conversation typically remains focused upon the present therapeutic challenges faced by older adults.

In instances where spiritual growth is the primary focus, clients should typically be referred to clergy (Richards \& Bergin, 2005). It is important to note that clergy are experts in spirituality, and often have training in mental health issues. For instance, the American Association of Pastoral Counselors requires members to have a bachelor's 
degree, a three year professional degree from a seminary, and a specialized master's or doctorate in a mental health discipline. In the same way that social workers should avoid dispensing medical or legal advice, dispensing spiritual advice should also be avoided. Clients' interests are typically served more appropriately by providing services within the boundaries of one's area of professional competence.

By way of qualification, it should be noted that the clear demarcation of professional responsibilities between social workers and clergy is often relatively complex in actual practice (Miller, 2003). For instance, an older adult may be wrestling with spiritual issues related to their clergy member and desire a safe neutral environment in which to process the issues. In other cases, spiritual growth may be intertwined with symptom amelioration (Sullivan, 2009). In yet other situations, gerontological workers may be the only helping professionals whom older clients trust to address spiritual issues (Anderson, Anderson, \& Felsenthal, 1993). While it is important to acknowledge this complexity, the limits of one's professional expertise should always be borne in mind and steps should typically be taken to avoid assuming dual relationships (Richards \& Bergin, 2005).

This same basic principle also applies to interventions. When constructing spiritual interventions-or therapeutically oriented strategies that incorporate spirituality or religion as a central component of the intervention-it is important to remain within the parameters of one's clinical expertise (Drake, Jonson-Reid, Hovmand \& Zayas, 2007; Hodge, 2006b). The degree of training and experience with a given intervention should be considered in the selection process (Canda \& Furman, 2010). Spiritual interventions should only be used when workers are reasonably confident that the intervention can be implemented in a professional manner (Richards \& Bergin, 2005).

For example, in the same way that gerontological workers trained in cognitive behavioral therapy (CBT) might avoid using psychodynamic interventions, workers should refrain from using spiritual interventions that fall outside the boundaries of their professional training. This is a particularly significant issue in light of the limited training on spirituality most workers may have received during their graduate education (Murdock, 2005; Sheridan, 2009). Clients have a right to expect that workers have some degree of expertise in the interventions used.

Thus, if gerontological workers lack sufficient training in an intervention, referral to a practitioner with the necessary proficiency should be considered (Reamer, 2006). Similarly, if the exploration of spirituality cannot be linked to some therapeutic goal that falls within the preview of a social worker's responsibilities, then referral to clergy is typically appropriate (Gilbert, 2000; -Tan, 2003).

When exploring the issue of referral it is important to ensure that clergy share older adults' value system. As implied above, beliefs and practices can differ substantially within a given tradition. It should not be assumed, for instance, that a Methodist pastor would be a good referral with a Methodist client, just because the client self-identifies as Methodist (Hunter, 1991). To help ensure client autonomy is respected, steps should be taken to help ensure some degree of value congruence exists between older adults and potential referrals. As is the case with many issues, older adults themselves are often 
excellent resources and can point gerontological workers in the right direction regarding possible referrals.

Indeed, clients' spiritual expertise can often supplement workers' professional competence. As is the case with spiritual competence, professional competence is best understood as a continuous, rather than a dichotomous, construct. By virtue of their professional training and experience, gerontological workers typically have some degree of competence with an array of different practice strategies. Moderate levels of competence can often be supplemented with the knowledge of clients, who can typically be considered experts on their own spirituality.

Through such a collaborative process, spirituality can often be integrated into treatment (Nielsen, 2004). Consider, for example, a worker trained in CBT who is professionally proficient in constructing health-promoting self-statements to alleviate problems. Such a practitioner may be able to co-construct spiritually modified selfstatements in a professional manner when working with a spiritually motivated older adult, particularly if the practitioner is conversant with the norms of the client's spiritual tradition (Ellis, 2000; Hodge, 2006b; Nielsen, 2004).

Similarly, collaborating with clergy can be helpful in developing spiritual interventions (Miller, 2003). As specialists in spirituality, clergy can often provide helpful insights into spiritual beliefs and practices that may be relevant to the challenges encountered by clients. Engaging spiritual specialists from older adults' religious communities can aid in the process of constructing professionally designed, culturally relevant interventions.

It may be helpful to note that some research suggests that many clergy are open to working with social workers (Galek, Flannelly, Koenig, \& Fogg, 2007; Harr et al., 2006; Oppenheimer et al., 2004). Gerontological workers can facilitate collaborative relationships by pro-actively implementing a number of strategies (Harr et al., 2006). Included among these strategies are communicating: respect for clergy's status as professionals, deference to clergy's specialized knowledge in spirituality, recognition regarding the importance of spirituality as a distinct dimension of human existence on a par with emotional/cognitive dimensions, and interacting with clergy as co-equals.

When considering potential collaborations or referrals, it is important that clients fully consent to such associations. Although clients generally view their religious communities positively, in some cases conflicts can exist. Such conflicts may be due to value incongruence, interpersonal problems, or other issues. As implied above, it may be appropriate to discuss clients' spiritual concerns in such situations. It may be helpful, however, to obtain supervision in such cases from someone with some degree of expertise in spirituality.

\section{CONCLUSION}

Many older adults believe that spirituality plays an important role in helping them address the challenges they face in later life (Cabassa, 2007; Lawrence et al., 2006). Research suggests that most gerontological social workers are sensitive to these beliefs, 
cognizant of their lack of training, and desirous of becoming more proficient in this area (Murdock, 2005). According to one study $(N=299)$, approximately $75 \%$ of gerontological social workers wanted to become more sophisticated about the use of spirituality in practice (Murdock, 2005).

Toward this goal, three principles that may be particularly salient in work with older adults were discussed: client autonomy, spiritual competence, and professional competence (Canda et al., 2004; Murdock, 2005; Sheridan, 2009). It is important to emphasize the inter-connected nature of these three guidelines. It is much easier to respect older adults' autonomy if one develops spiritual competence in the client's tradition. Similarly, professional competence can often be supplemented if one has sufficient fluency in the norms of an older adult's tradition and the client desires to work with the practitioner to co-construct spiritual interventions. Engaging clients in the therapeutic process respects their autonomy and can enhance outcomes.

Indeed, this is the bottom line-client welfare. In other words, the point of ethical principles is to ensure clients' best interests are prioritized. The application of these and other relevant ethical guidelines in practice settings will assist workers to interact with older adults in a professional and ethical manner that helps safeguard and enhance their well-being.

\section{References}

Aldwin, C., Park, C. L., \& Spiro, A. (Eds.). (2007). Handbook of health psychology and aging. New York: Guilford Press.

Anderson, J. M., Anderson, L. J., \& Felsenthal, G. (1993). Pastoral needs and support within an inpatient rehabilitation unit. Archives of Physical Medicine and Rehabilitation, 74, 574-578.

Barusch, A. S. (1999). Religion, adversity and age: Religious experiences of low-income elderly women. Journal of Sociology and Social Welfare, 26(1), 125-142.

Benes, K. M., Walsh, J. M., McMinn, M. R., Dominquez, A. W., \& Aikins, D. C. (2000). Psychology and the church: An exemplar of psychologist-clergy collaboration. Professional Psychology: Research and Practice, 31(5), 515-520.

Berkman, B. J., Maramaldi, P., Breon, E. A., \& Howe, J. L. (2002). Social work gerontological assessment revisited. Journal of Gerontological Social Work, 40(1/2), $1-14$.

Brennan, M. (2002). Spirituality and psychosocial development in middle-age and older adults with vision loss. Journal of Adult Development, 9(1), 31-46.

Cabassa, L. J. (2007). Latino immigrant men's perceptions of depression and attitudes toward help seeking. Hispanic Journal of Behavioral Sciences, 29(4), 492-509.

Canda, E. R., \& Furman, L. D. (1999). Spiritual diversity in social work practice. New York: The Free Press. 
Canda, E. R., \& Furman, L. D. (2010). Spiritual diversity in social work practice: The heart of helping ( $2^{\text {nd }}$ ed.). New York: Oxford University Press.

Canda, E. R., Nakashima, M., \& Furman, L. D. (2004). Ethical considerations about spirituality in social work: Insights from a national qualitative survey. Families in Society, 85(1), 27-35.

Derezotes, D. S. (2006). Spiritually oriented social work practice. Boston: Pearson.

Drake, B., Jonson-Reid, M., Hovmand, P., \& Zayas, L. H. (2007). Adopting and teaching evidence-based practice in master's-level social work programs. Journal of Social Work Education, 43(3), 431-446.

Eck, D. L. (2001). A new religious America. New York: HaperCollins.

Edwards, L. C., Brian, L., McMinn, M. R., \& Dominguez, A. W. (1999). Examples of collaboration between psychologists and clergy. Professional Psychology: Research and Practice, 30(6), 547-551.

Ellis, A. (2000). Can rational emotive behavior therapy be effectively used with people who have devout beliefs in God and religion? Professional Psychology: Research and Practice, 31(1), 29-33.

Frame, M. W. (2003). Integrating religion and spirituality into counseling. Pacific Grove, CA: Brooks/Cole.

Galek, K., Flannelly, K. J., Koenig, H. G., \& Fogg, S. L. (2007). Referrals to chaplains: The role of religion and spirituality in healthcare settings. Mental Health, Religion \& Culture, 10(4), 363-377.

Gallup, G. J., \& Jones, T. (2000). The next American spirituality: Finding God in the twenty-first century. Colorado Springs: Victor.

Gallup, G. J., \& Lindsay, D. M. (1999). Surveying the religious landscape. Harrisburg, PA: Morehouse Publishing.

Ganje-Fling, M. A., \& McCarthy, P. R. (1991). A comparative analysis of spiritual direction and psychotherapy. Journal of Psychology and Theology, 19(1), 103-117.

Genia, V. (2000). Religious issues in secularly based psychotherapy. Counseling and Values, 44(3), 213-221.

Geppert, C., Bogenschutz, M. P., \& Miller, W. R. (2007). Development of a bibliography on religion, spirituality, and addiction. Drug and Alcohol Review, 26(4), 389-395.

Gilbert, M. (2000). Spirituality in social work groups: Practitioners speak out. Social Work with Groups, 22(4), 67-84.

Ginsberg, L. (1999). Reviewers, orthodoxy, and the passion to publish. Research on Social Work Practice, 9(1), 100-103. 
Harr, C., Openshaw, L., \& Moore, B. (2006). Moving toward effective interdisciplinary collaborations to address spirituality: Chaplains' perspectives on working with social workers. Arête, 30(1), 101-111.

Hodge, D. R. (2001). Spiritual genograms: A generational approach to assessing spirituality. Families in Society, 82(1), 35-48.

Hodge, D. R. (2002). Working with Muslim youth: Understanding the values and beliefs of Islamic discourse. Children and Schools, 24(1), 6-20.

Hodge, D. R. (2003). The challenge of spiritual diversity: Can social work facilitate an inclusive environment? Families in Society, 84(3), 348-358.

Hodge, D. R. (2004). Why conduct a spiritual assessment? A theoretical rationale for assessment. Advances in Social Work, 5(2), 183-196.

Hodge, D. R. (2005a). Spiritual life maps: A client-centered pictorial instrument for spiritual assessment, planning, and intervention. Social Work, 50(1), 77-87.

Hodge, D. R. (2005b). Spiritual assessment in marital and family therapy: A methodological framework for selecting between six qualitative assessment tools. Journal of Marital and Family Therapy, 31(4), 341-356.

Hodge, D. R. (2005c). Spiritual ecograms: A new assessment instrument for identifying clients' spiritual strengths in space and across time. Families in Society, 86(2), 287296.

Hodge, D. R. (2005d). Developing a spiritual assessment toolbox: A discussion of the strengths and limitations of five different assessment methods. Health and Social Work, 30(4), 314-323.

Hodge, D. R. (2005e). Social work and the house of Islam: Orienting practitioners to the beliefs and values of Muslims in the United States. Social Work, 50(2), 162-173.

Hodge, D. R. (2006a). A template for spiritual assessment: A review of the JCAHO requirements and guidelines for implementation. Social Work, 51(4), 317-326.

Hodge, D. R. (2006b). Spiritually modified cognitive therapy: A review of the literature. Social Work, 51(2), 157-166.

Hodge, D. R., \& Bushfield, S. (2006). Developing spiritual competence in practice. Journal of Ethnic and Cultural Diversity in Social Work, 15(3/4), 101-127.

Hodge, D. R., \& Derezotes, D. S. (2008). Postmodernism and spirituality: Some pedagogical implications for teaching content on spirituality. Journal of Social Work Education, 44(1), 103-123.

Hodge, D. R., \& Williams, T. R. (2002). Assessing African American spirituality with spiritual eco-maps. Families in Society, 83(5/6), 585-595.

Hunter, J. D. (1991). Culture wars. New York: Basic Books. 
Keyes, C. L. M., \& Reitzes, D. C. (2007). The role of religious identity in the mental health of older working and retired adults. Aging and Mental Health, 11(4), 434-443.

Koenig, H., G. (Ed.). (1998). Handbook of religion and mental health. New York: Academic Press.

Koenig, H., G. (2007a). Religion and depression in older medical inpatients. American Journal of Geriatric Psychiatry, 15(4), 282-291.

Koenig, H. G. (2007b). Spirituality in patient care $\left(2^{\text {nd }}\right.$ ed.). Philadelphia: Templeton Foundation Press.

Koenig, H., G., Larson, D. B., \& Matthews, D. A. (1996). Religion and psychotherapy with older adults. Journal of Geriatric Psychiatry, 29(2), 155-184.

Koenig, H. G., McCullough, M. E., \& Larson, D. B. (2001). Handbook of religion and health. New York: Oxford University Press.

Krause, N. (2009). Lifetime trauma, prayer, and psychological distress in late life. International Journal for the Psychology of Religion, 19(1), 55-72.

Lawrence, V., Banerjee, S., Bhugra, D., Sangha, K., Turner, S., \& Murray, J. (2006). Coping with depression in later life: A qualitative study of help-seeking in three ethnic groups. Psychological Medicine, 36, 1375-1383.

Lewis, M. M. (2001). Spirituality, counseling, and the elderly: An introduction to the spiritual life review. Journal of Adult Development, 8(4), 231-240.

Melton, J. G. (2003). The encyclopedia of American religions ( $7^{\text {th }}$ ed.). Detroit, MI: Gale Research.

Miller, G. (2003). Incorporating spirituality in counseling and psychotherapy. Hoboken, NJ: John Wiley \& Sons.

Miller, W. R. (1998). Researching the spiritual dimensions of alcohol and other drug problems. Addiction, 93(7), 979-990.

Moberg, D. O. (2005). Research in spirituality, religion, and aging. Journal of Gerontological Social Work, 45(1/2), 11-40.

Murdock, V. (2005). Guided by ethics: Religion and spirituality in gerontological social work practice. Journal of Gerontological Social Work, 45(1/2), 131-154.

Musick, M. A., Traphagan, J. W., Koenig, H. G., \& Larson, D. B. (2000). Spirituality in physical health and aging. Journal of Adult Development, 7(2), 73-86.

NASW Code of Ethics. (1999). Retrieved 12/06/2009, from http://www.socialworkers.org/pubs/code/code.asp.

Nelson-Becker, H. (2005). Religion and coping in older adults: A social work perspective. Journal of Gerontological Social Work, 45(1/2), 51-67. 
Nelson-Becker, H., Nakashima, M., \& Canda, E. R. (2007). Spiritual assessment in aging: A framework for clinicians. Journal of Gerontological Social Work, 48(3/4), 331-347.

Newport, F. (2006). Religion most important to Blacks, women, and older Americans. Retrieved 06/06/2009, from http://www.gallup.com/poll/25585/religion-mostimportant-blacks-women-older-americans.aspx.

Nielsen, S. L. (2004). A Mormon rational emotive behavior therapist attempts Qur'anic rational emotive behavior therapy. In P. S. Richards \& A. E. Bergin (Eds.), Casebook for a spiritual strategy in counseling and psychotherapy (pp. 213-230). Washington, DC: American Psychological Association.

Oppenheimer, J. E., Flannelly, K. J., \& Weaver, A. J. (2004). A comparative analysis of the psychological literature on collaboration between clergy and mental-health professionals--perspectives from secular and religious journals: 1970-1999. Pastoral Psychology, 53(2), 153-162.

Rajagopal, D., MacKenzie, E., Bailey, C., \& Lavizzo-Mourey, R. (2002). The effectiveness of a spiritually-based intervention to alleviate subsyndromal anxiety and minor depression among older adults. Journal of Religion and Health, 41(2), 153-166.

Reamer, F. G. (2006). Social work values and ethics ( $3^{\text {rd }}$ ed.). New York: Columbia University Press.

Resnicow, K., Soler, R., Braithwaite, R. L., Ahluwalia, J. S., \& Butler, J. (2000). Culturally sensitivity in substance use prevention. Journal of Community Psychology, 28(3), 271-290.

Richards, P. S., \& Bergin, A. E. (Eds.). (2000). Handbook of psychotherapy and religious diversity. Washington, DC: American Psychological Association.

Richards, P. S., \& Bergin, A. E. (2005). A spiritual strategy for counseling and psychotherapy ( $2^{\text {nd }}$ ed.). Washington, DC: American Psychological Association.

Sheridan, M. (2009). Ethical issues in the use of spiritually based interventions in social work practice: What we are doing and why. Journal of Religion and Spirituality in Social Work, 28(1/2), 99-126.

Smith, G. H. (2002). Religious freedom and the challenge of terrorism. Brigham Young University Law Review, pp. 205-216.

Smith, T. W., \& Seokho, K. (2005). The vanishing Protestant majority. Journal for the Scientific Study of Religion, 44(2), 211-223.

Sue, D., \& Sue, D. (2008). Counseling the culturally diverse: Theory and practice ( $^{\text {th }}$ ed.). Hoboken, NJ: John Wiley \& Sons.

Sullivan, W. P. (2009). Spirituality: A road to mental health or mental illness. Journal of Religion and Spirituality in Social Work, 28(1/2), 84-98. 
Tan, S.-Y. (2003). Integrating spiritual direction into psychotherapy: Ethical issues and guidelines. Journal of Psychology and Theology, 31(1), 14-23.

Taylor, R. J., Chatters, L. M., \& Jackson, J. S. (2007). Religious and spiritual involvement among older African Americans, Caribbean Blacks, and non-Hispanic Whites: Findings from the National Survey of American Life. Journal of Gerontology, 62B(4), S238-S250.

Tompkins, C. J., Larkin, H., \& Rosen, A. L. (2006). An analysis of social work textbooks for aging content: How well do social work foundation texts prepare students for our aging society? Journal of Social Work Education, 42(1), 3-23.

Van Hook, M., Hugen, B., \& Aguilar, M. A. (Eds.). (2001). Spirituality within religious traditions in social work practice. Pacific Grove, CA: Brooks/Cole.

Vance, D. E. (2006). Spirituality and living and aging with HIV: A pilot study. Journal of Religion, Spirituality and Aging, 19(1), 57-74.

Vink, D., Aartsen, M. J., \& Schoevers, R. A. (2008). Risk factors for anxiety and depression in the elderly: A review. Journal of Affective Disorders, 106, 29-44.

Wuthnow, R. (2007). After the baby boomers: How twenty- and thirty-somethings are shaping the future of American religion. Princeton, NJ: Princeton University Press.

Yoon, D. P., \& Lee, E.-K. O. (2007). The impact of religiousness, spirituality, and social support on psychological well-being among older adults in rural areas. Journal of Gerontological Social Work, 48(3/4), 281-298.

Zhang, J.-G., Ishikawa-Takata, K., Yamazaki, H., Morita, T., \& Ohta, T. (2006). The effects of Tai Chi Chuan on physiological function and fear of falling in the less robust elderly: An intervention study for preventing falls. Archives of Gerontology and Geriatrics, 42(2), 107-116.

\section{Author's note:}

Address correspondence to: David R. Hodge, Ph.D., School of Social Work, CoPP, Arizona State University, Mail Code 3920, 411 N. Central Avenue, Suite 800, Phoenix, AZ 85004-0689. 